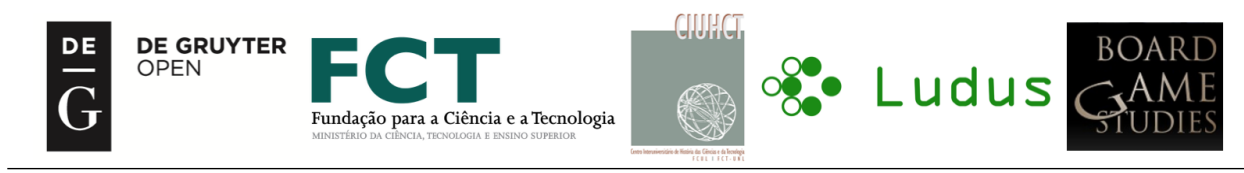

\title{
Theory of the introduction of Shogi via Southeast Asia: Viewed from the forms of Makruk pieces - Study of the reversing of promoted Bia pieces
}

\author{
Yasuji Shimizu
}

\section{Introduction}

In the late 19th century, the similarity between Thai Makruk and Japanese Shogi was pointed out for the first time (Falkener 1892). Subsequently, there was a negative view that the similarity was just coincidental, while in 1971, Alex Randolph again focused on the similarity between Makruk and Japanese Shogi, and wrote that Shogi was introduced to Japan via Southeast Asia (Randolph 1971). Different from past theories, Randolph's work was published in Japan and gave rise to followers of Randolph in Japan who thought that the introduction of Japanese Shogi had some relation to Shogilike games in Southeast Asia (Masukawa 1977; Ouchi 1986). Concerning the introduction of Shogi to Japan, it had been vaguely thought that the game would have been introduced from China or the Korean Peninsula. However, as the similarity between Shogi-like games in Southeast Asia and Japanese Shogi was pointed out, a new research perspective was added whereby the long-distance Marine Silk Road trade might have some connection with the introduction of Shogi to Japan.

Initially, Randolph and his followers assumed the existence of ports of call between Southeast Asia and Japan, while they apparently supposed that Shogi-like games in Southeast Asia had a direct influence on the establishment of Japanese Shogi. Because the current Xiangqi in China is very different from the present Japanese Shogi, they considered that Shogi-like games in Southeast Asia had not become widespread in the Chinese continent. However, there are only a few products of culture related to Southeast Asia in ancient times, and there are no records showing that ships from Southeast Asia stopped at ports of call in China before coming to the Japanese archipelago. Due to the lack of evidence, the theory that Japanese Shogi was introduced from Southeast Asia has changed as time has passed. As 
Yoshinori Kimura advocated, it came to be considered that Shogi-like games in Southeast Asia were introduced to southern China and then introduced to Japan (Kimura 2001). Generally, there are the two conflicting ideas that Japanese Shogi had its origin either in China or in Southeast Asia. People who believe Shogi-like games came to Japan from China assume that Shogilike games first came to China from India without going through Southeast Asia and then came to Japan. Against this idea, it would be safe to assume that those who believe that Japanese Shogi has its origin in Southeast Asia think the following way: Shogi-like games first came to Southeast Asia from India. They were then introduced to southern China and took root in society. After that, the games were introduced to Japan. Therefore, according to the latter way of thinking, we should consider that Shogi-like games came to Japan via Southeast Asia, rather than having their origin in Southeast Asia.

Among historic materials concerning Shogi-like games in Southeast Asia, an artifact of certainty is a relief at Angkor Wat, which dates back to the mid-12th century. Meanwhile, in China, Shogi-like games were mentioned in the Chinese fantasy novel Xuan guai lu written in the early 9th century, while in Japan, there is the novel Shin-Sarugoki, written in the mid-11th century, as well as Kohfukuji Temple Shogi pieces made in the late 11th century as archaeological material (Shimizu and Oguri 1992). With these ages in mind, it is difficult to believe that Shogi-like games came to Southeast Asia earlier than to East Asia. Despite this, many people believe that Shogi-like games came to Japan via Southeast Asia based on three commonalities between Makruk and Japanese Shogi, which were precisely pointed out by Alex Randolph (Randolph 1971). The first commonality is "the initial placement of pieces equivalent to pawns in the third rank." The second is "the issue of zou (movements common to pieces equivalent to the Silver General.)" And the third is the "reversing of promoted pieces equivalent to pawns." Due to these important commonalities, even though historic Shogi-related materials in Southeast Asia are newer than those existing in East Asia, the existence of Shogi-like games in Southeast Asia cannot be completely denied even in ages when no relevant materials are confirmed.

However, with regard to "the initial placement of pieces equivalent to pawns in the third rank," according to the study of Yoshinori Kimura, it is reasonable to consider that there was a predecessor to the current Xiangqi, which also had "the initial placement of pieces equivalent to pawns in the third rank" (Kimura 2001). In the current Xiangqi, pieces equivalent to pawns are placed in the fourth rank, while it is quite possible that they were placed in the third rank before the Cannon piece was introduced. Therefore, 
it is impossible to conclude that Japanese Shogi was influenced by Southeast Asia's Shogi-like games by the reason of "the initial placement of pieces equivalent to pawns in the third rank."

Concerning "the issue of zou," there is a record showing the existence of a piece that makes the same movements as the Silver General in the 12th century in northern India, so we cannot conclude that Shogi-like games came to Japan via Southeast Asia (Murray 1913; Shimizu 2013). The Southeast Asia theory appears to be based on the idea that, because Southeast Asia is geographically closer to India, Shogi-like games were introduced to the region earlier than to China. However, such an understanding sounds too simple. Regarding the introduction of Buddhism, Buddhist culture took root in China earlier than in Southeast Asia. With regard to events that exist both in China and Southeast Asia, because Chinese people stayed in Southeast Asia in those days as seen in a relief in Angkor Thom, it is quite possible that Shogi-like games came to Southeast Asia from China, and vice versa.

Regarding the remaining commonality, "the reversing of promoted pieces equivalent to pawns," there is no evidence that the rule was applied to Xiangqi in China. However, even the Southeast Asia theory supposes that Shogi became widespread to a certain extent in southern China and that pieces had been flattened and made employ characters before coming to Japan. So, the fact that the exciting reversing rule of promoted pieces, which once took root in southern China, did not have any influence on the current Xiangqi can support the assumption that Shogi-like games were not introduced to southern China from Southeast Asia. If the rule had been established in Japan, understanding the establishment of the reversing rule of promoted Bia pieces in Thailand would become a problem. Concerning the establishment of the rule, while many Japantowns were created in Southeast Asia at the end of the Middle Ages and the Early Modern period, it is assumed that the establishment resulted from the influence of Japanese Shogi on Makruk-type Shogi games in Thailand in the period (Matsuoka 2009). On the other hand, it also is possible to consider that the establishment of the reversing rule of promoted pieces in Japan and Southeast Asia had nothing to do with each other, just as Murray believed that the similarity between Makruk and Japanese Shogi was just coincidental (Shimizu 2013). If reversible pieces, such as those in the form of plates, are employed, it would not be very difficult to advance the idea of the reversing rule.

When considering the prerequisite conditions for the Southeast Asia theory in this way, it is obvious that the rule of "reversing of promoted pieces equivalent to pawns" is an important key. In this article, I will conduct a 


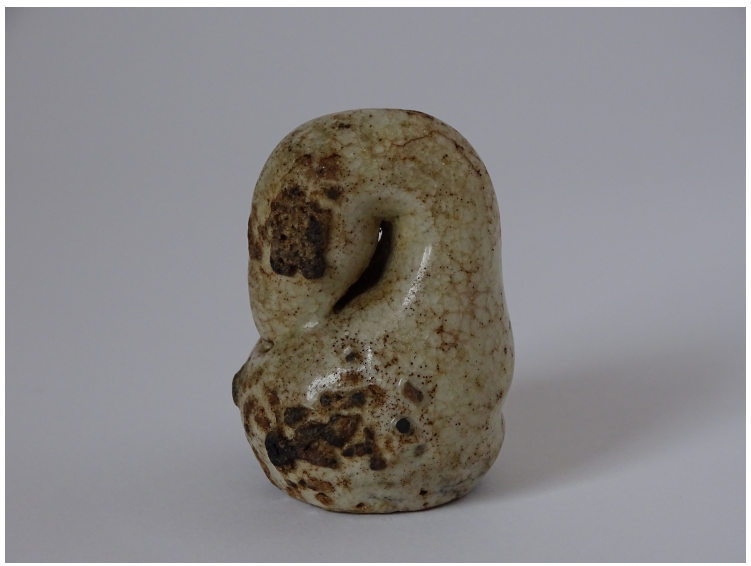

Figure 1

study concerning the forms of Bia pieces by focusing on Makruk pieces made in the period from the 12 th to 16 th centuries because, in Southeast Asia, they exist only in Thailand at present, and examine when the reversing rule in Makruk was established.

\section{Discussion of pieces owned by the Bangkok Na- tional Museum}

There are 14 exhibited Makruk pieces owned by the Bangkok National Museum. They are believed to have been made at a kiln in Si Satchanalai in the 15 th and 16 th centuries 11 There are several pieces of the same form, and the paste and glaze used for the pieces suggest that they are highly likely to have been made in the same kiln.

Different from Japanese Shogi pieces, Makruk pieces do not have characters that show the name of each piece, so it is unknown what kinds the Museum pieces are. However, it is possible to elucidate the kinds by comparing them with current Makruk pieces. In order to make a distinction between friend and foe for the Bangkok Museum pieces, a bronzed glaze is partly used for the pieces. The three Ma pieces have representational forms so they are easy to distinguish (Figure 1).

Ruea pieces are the second-easiest kind to determine. Other pieces have

\footnotetext{
${ }^{1}$ The age estimates for the pieces in the article were conducted by Pariwat Thammapreechakor, the director of the Southeast Asian Ceramic Museum.
} 


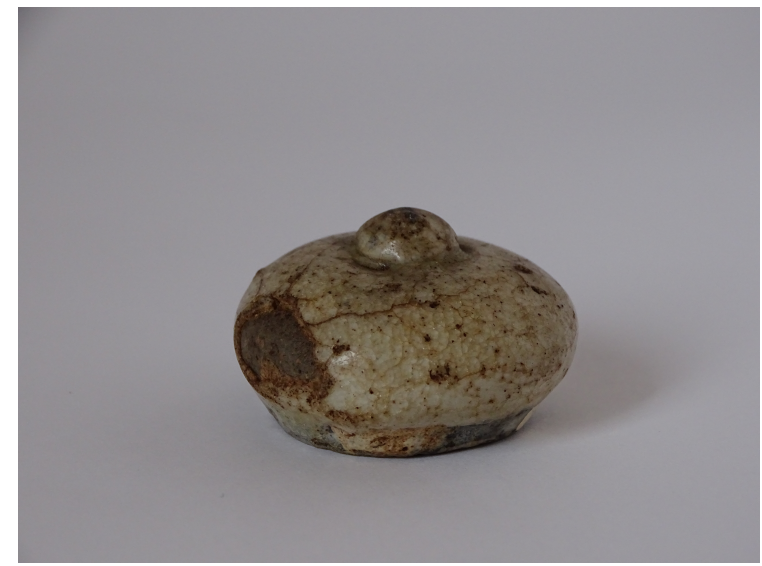

Figure 2

characteristics that the height is high compared to the base diameter, while there are four pieces whose base diameter is large and whose height is low. In current Makruk pieces, Ruea pieces have a similar form, so it is safe to assume that these four pieces are Ruea pieces (Figure 2). A Khun piece, equivalent to King, is the largest piece among the others in current Makruk pieces, so it is highly likely to be the same with past pieces. Based on this hypothesis, a piece whose front edge has a giboshi-like form and that has another bulbous part in the lower part can be considered to be a piece equivalent to Khun (Figure 3).

As for Khon and Met pieces, with current Makruk pieces, Met is rather smaller than Khon. However, there is only a little difference in height between the remaining two kinds of Bangkok Museum pieces, and their base diameters are not very different. Therefore, while it is difficult to decide their kinds only with the Museum pieces, by focusing on a small difference, it could be considered that the two smaller pieces that are cone-shaped pieces and loosely curved are Met pieces (Figure 4). Among pieces produced in Kalong, which will be discussed later, there are downsized cone-shaped pieces. This fact also supports the assumption that the previously noted pieces are Mets. The remaining three pieces having three bulbous parts are obviously Khon, and not Bia (Figure 5).

It is unfortunate that a Bia piece does not exist among the pieces at the Bangkok Museum. This is because a Bia piece is smaller than the other pieces and its form is not as exciting, so the Museum might have decided not to own the piece. However, in that case, the form of Bia pieces would 


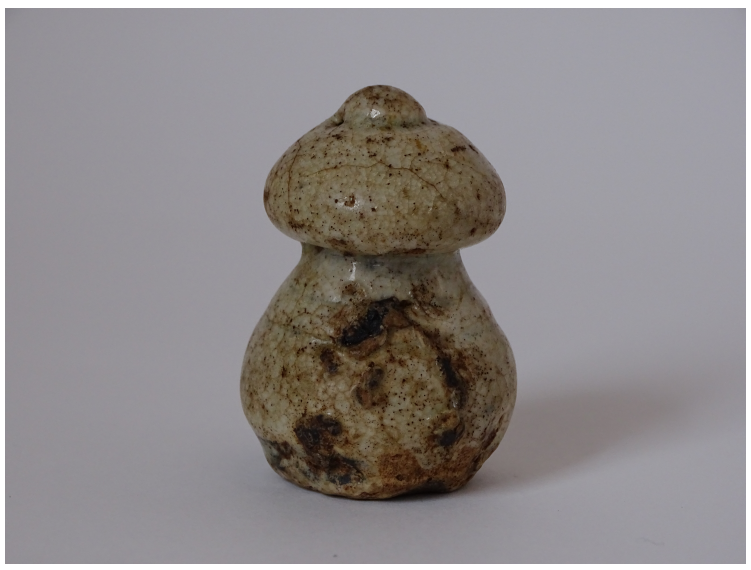

Figure 3

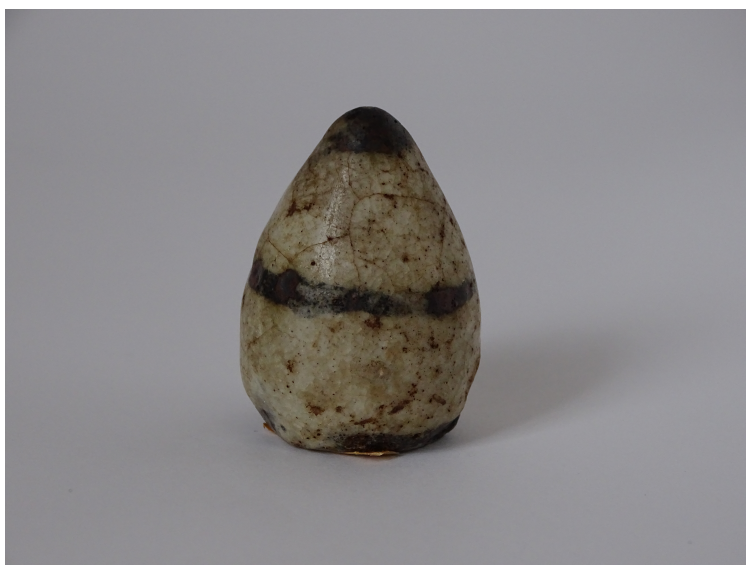

Figure 4 


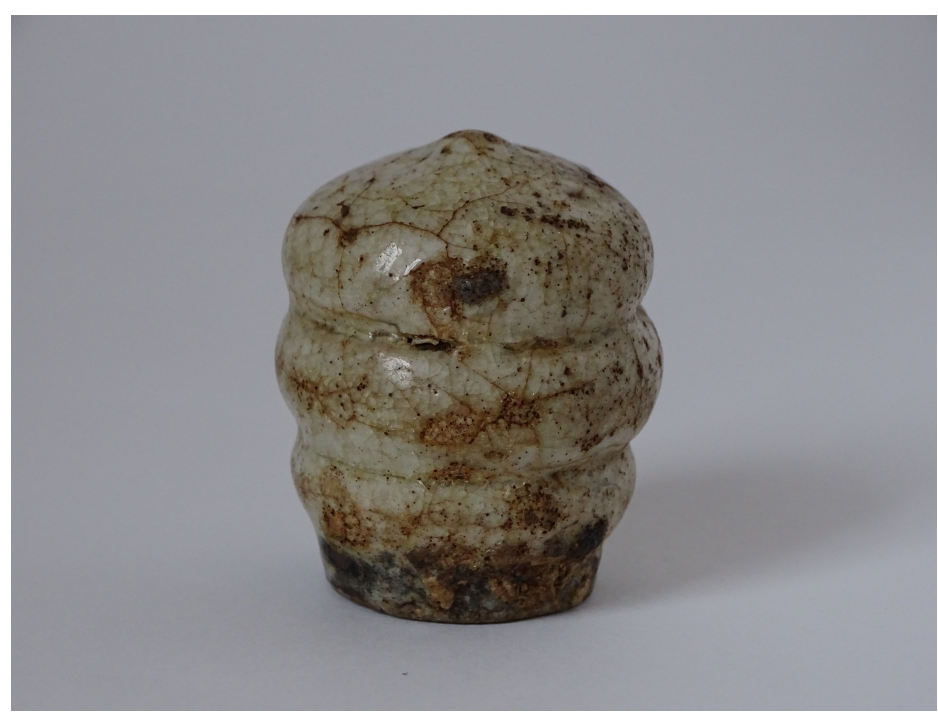

Figure 5

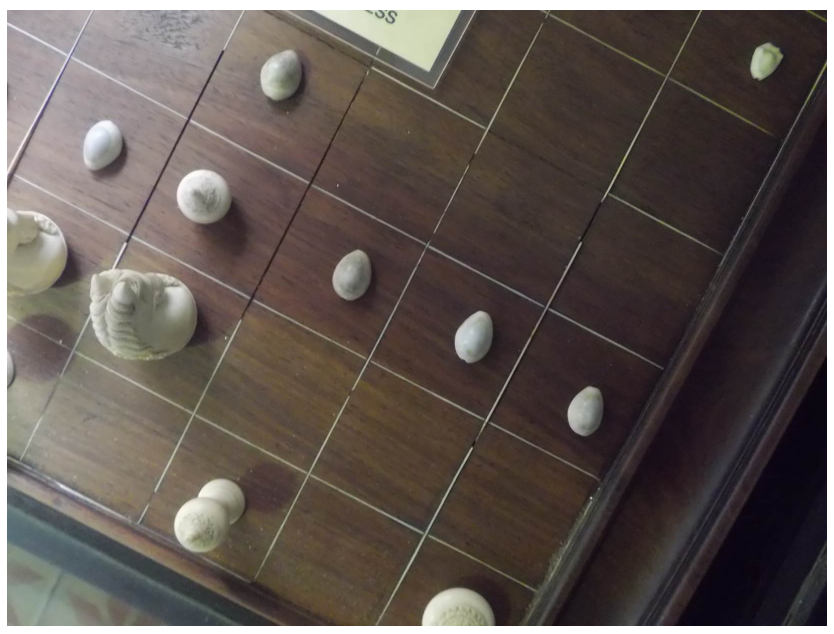

Figure 6 
not have a representational form such as a shell-like shape, but would have an abstract form resembling a standing statue. This is because, if the pieces had a shell-like form, they would have looked interesting and been likely to be collected. In addition, it seems unlikely that real treasury shells were used to make Bia pieces owned by the Bangkok Museum. Certainly, the Museum's exhibits include Bia pieces made of treasury shells and other standing statue-shaped pieces made of organic materials, such as woodcarved pieces, all of which were made in the Bangkok period (Figure 6). However, it is doubtful that such use of treasury shells dates back to ancient times because, if treasury shells were used in such a way constantly in those days, it would be natural that ceramic Bia pieces resembling treasury shells existed as pieces having a representational form such as Ma pieces. However, when looking at pieces produced in Kalong (from the 15th to 16th centuries), which will be discussed later, pieces resembling treasury shells have not so far been found. Bia pieces are the largest in number among other Makruk pieces, and unless they had a simple form, the pieces would have been collected by museums and others.

As described above, in addition to the factors of similar shape, paste, and glaze, the museum has two Khun pieces, two Met pieces, three Khon pieces, three Ma pieces, and four Ruea pieces, and does not have a kind of piece that exceeds the fixed number of each piece type in a set. So it is also possible that these pieces initially constituted a set of Makruk pieces.

\section{Discussion of Kalong pieces}

Among pieces owned by the Southeast Asian Ceramic Museum at Bangkok University, I conducted a study of pieces believed to have been made at a kiln in Kalong in Chiang Rai Province. These pieces were purchased, and it is unknown what they were like when excavated, while they are believed to have been made in the 15 th and 16 th centuries ${ }^{2}$ according to an expert appraisal. Chiang Rai Province is far from the capital of Bangkok, and its area was not included in the Sukhothai Kingdom or the Ayutthaya Kingdom in the period before the Thonburi Kingdom unified the nation, but belonged to the Lan Na Kingdom (A.D. 1292-1775.) The Lan Na Kingdom formed an alliance with the Sukhothai Kingdom and the Ayutthaya Kingdom, while it sometimes conflicted with them. In addition to complicated diplomatic relations, the Lan Na Kingdom was dominated by Burma at one time.

The question is whether the Kalong pieces are in the same system as the

\footnotetext{
${ }^{2}$ See previous note.
} 


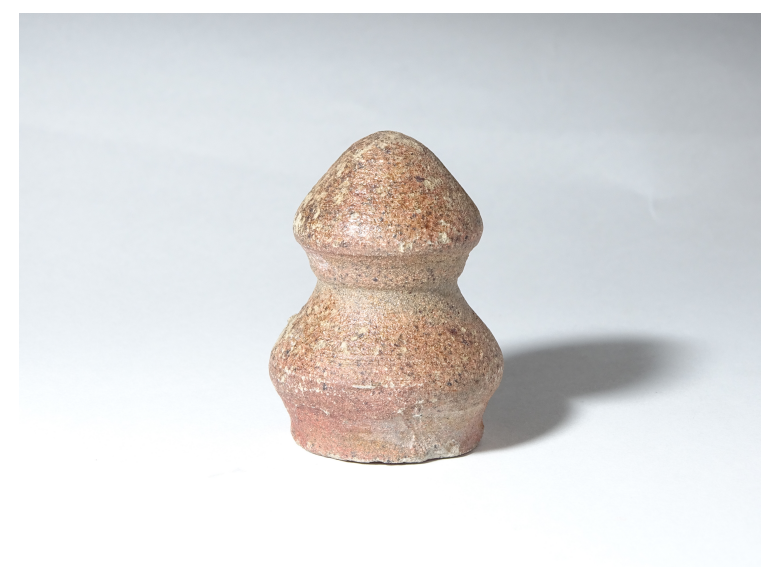

Figure 7

Makruk pieces, while it is safe to assume that they are in the same system based on several items of evidence. One indication is that a piece resembling a horse considered to be a Ma piece is the only kind having a representational form, which is in common with the current Makruk pieces and pieces owned by museums in Thailand. In addition, when discussing the Bangkok Museum pieces, there is a piece having a form resembling that of a Khun piece (Figure 7), a cone-shaped piece similar to a Met piece (Figure 8), and pieces similar to Khon (Figure 9) or Ruea pieces (Figure 10); some Kalong pieces are similar to those Museum pieces. However, the Kalong pieces are different from the Bangkok Museum pieces that can be considered to constitute a set, and they appear to be a collection of pieces having different origins. Therefore, it is difficult to determine the names of the Kalong pieces besides those having a form similar to that of the Museum pieces and those having a standing statue-shaped form like a Ma piece resembling a horse. The distinction between friend and foe is made by different use of glaze, same as the Bangkok Museum pieces.

Different from the Bangkok Museum pieces, the Kalong pieces include those considered to be Bia pieces having a small base of about two centimeters in diameter and being low in height. The base of these pieces is flat, but the upper part is round, which looks like manju steamed bread (Figure 11). I reversed the piece to confirm the stability, but the piece was not stable due to the round-shaped upper part (Figure 12). Only the upper part of one example had a relatively loose round, so the base part was almost flat after being reversed. Besides these pieces, there was a cone-shaped piece 


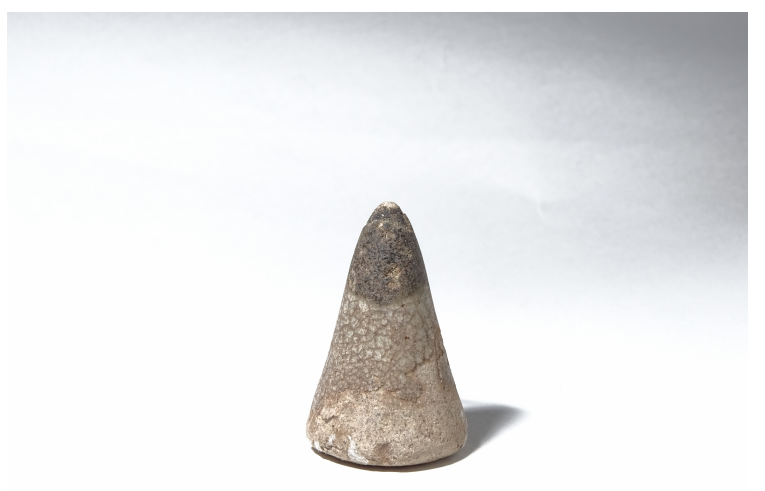

Figure 8

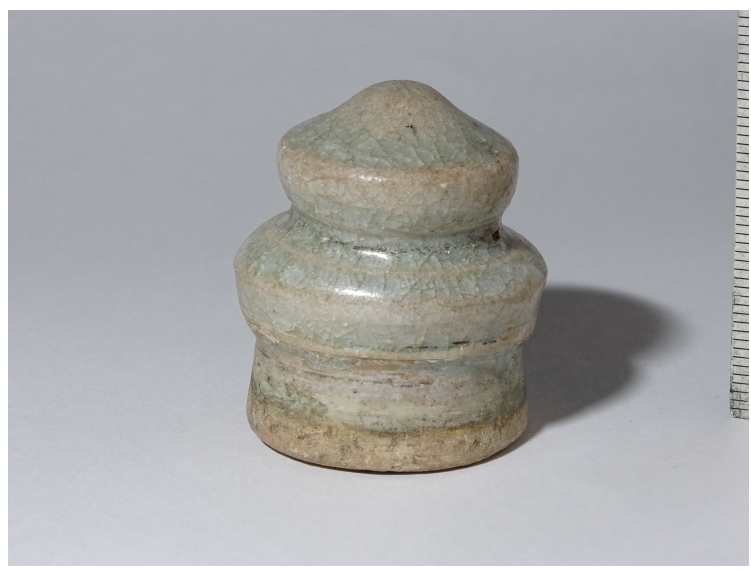

Figure 9 


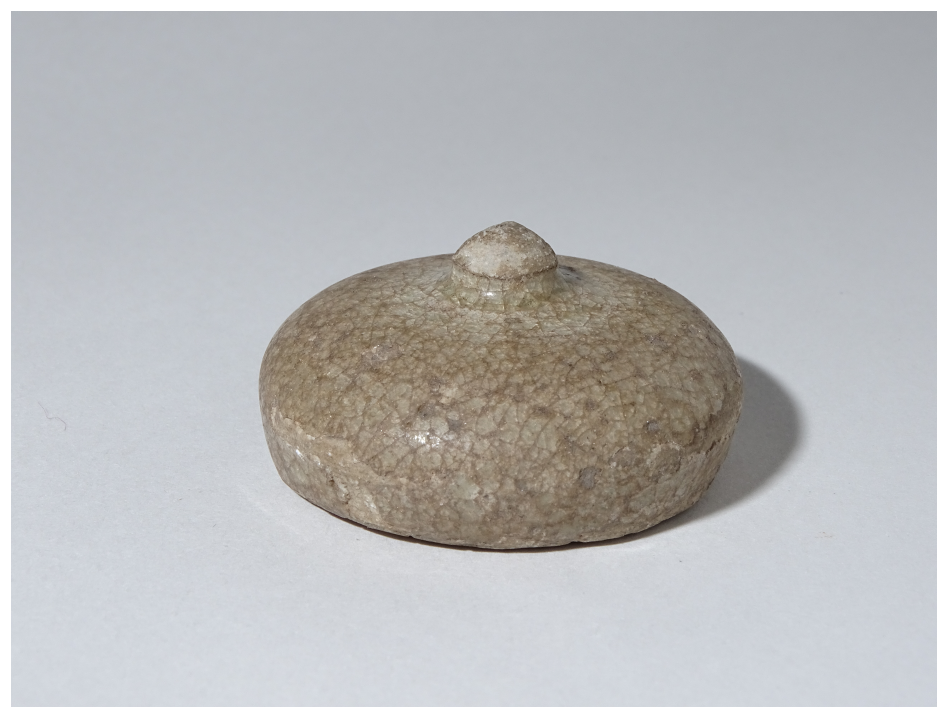

Figure 10

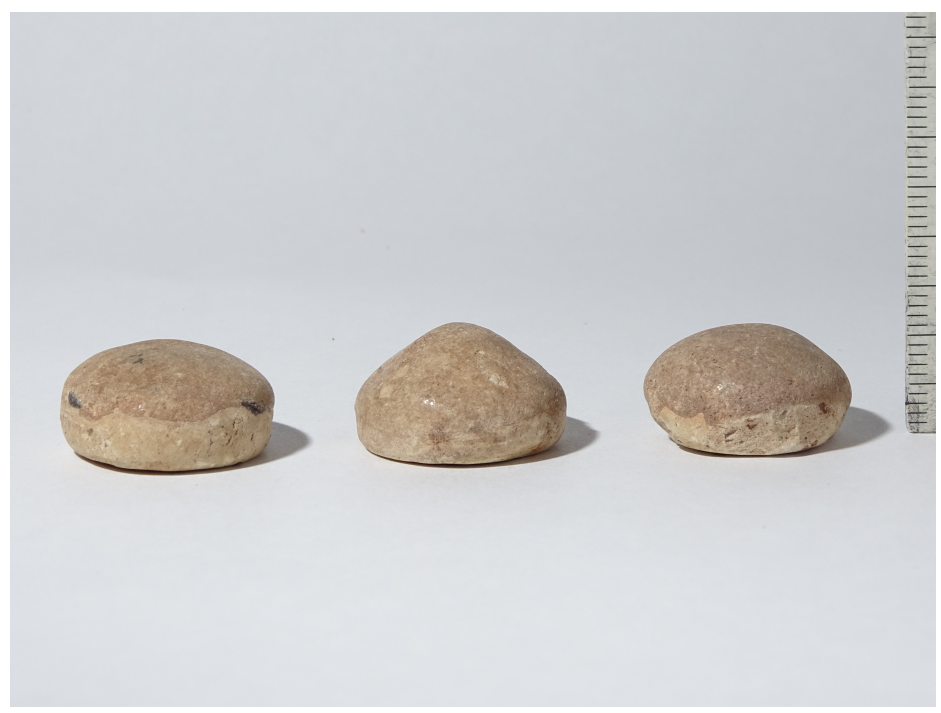

Figure 11

Board Game Studies Journal 11, pp. 53-71 DOI 10.1515/bgs-2017-0002 


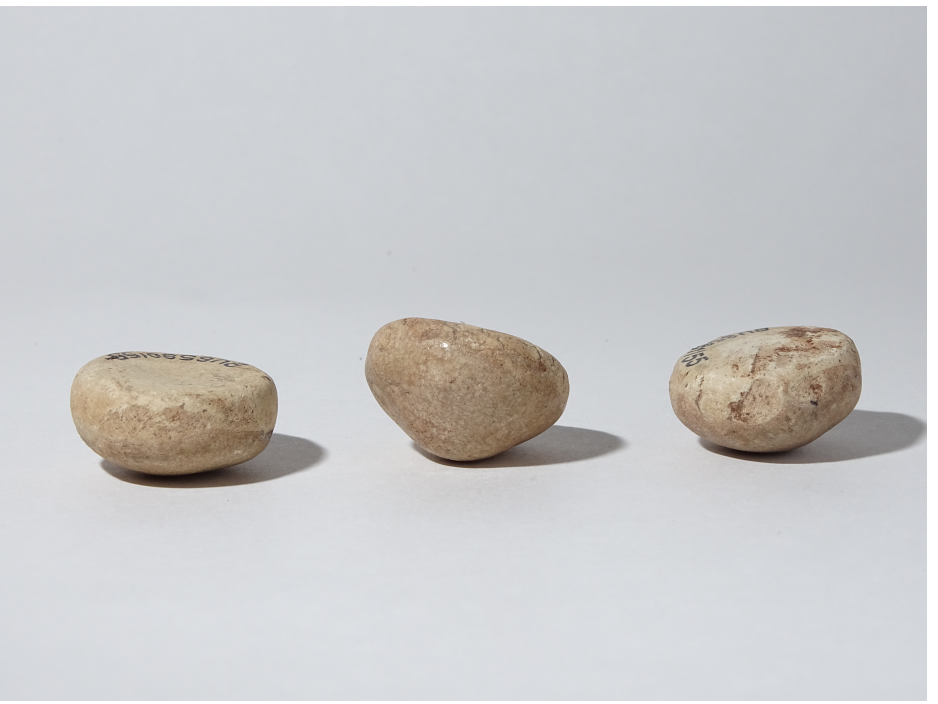

Figure 12

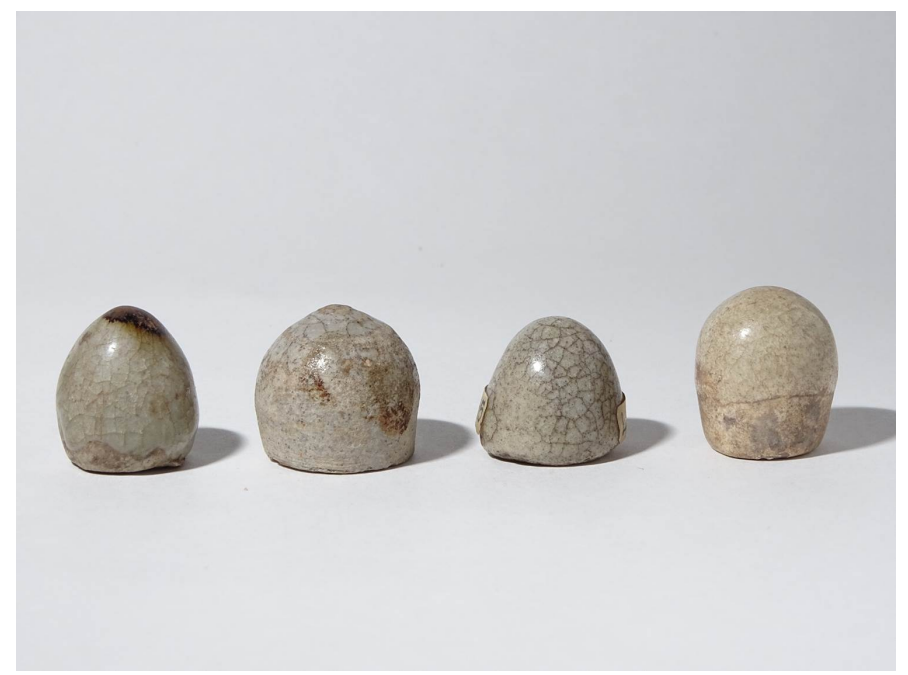

Figure 13 
whose base diameter was almost the same but whose top part was round (Figure 13). This piece has a smaller base diameter and a lower height than those previously determined to be Met pieces. From its form, it could be a further downsized Met piece. If it is a Bia piece, it cannot be used when reversed. In addition, there is a slightly wide cylindrical piece that has a small base diameter and a projection on the top part; the base diameter suggests that the piece could be a Bia piece $3^{3}$ It also could be a Met piece, but its base diameter is smaller than that of the manju-shaped Bia piece (Figure 14, Figure 15), so if the piece is a Bia piece, reversing a promoted piece is impossible.

While I examined possible Bia pieces among Kalong pieces, it was found that their shapes were not stable when reversed. The current Makruk pieces, many of which are plastic pieces, have a shape that is stable when reversed. Historically, in some cases, treasury shells such as those seen in exhibits might be used as Bia pieces. However, if the upper part of a treasury shell was made flat, it would have created a hole and spoiled its appearance. In contrast, ceramic pieces have high plasticity, so it is easy to make the upper part flat. Concerning the distinction between the face and reverse sides, it is easy to tell them apart by the existence of glaze and other factors. Based on these ideas, I suggest that the Kalong pieces are not stable when reversed because Makruk in the Lan Na Kingdom in the 15th and 16th centuries had not introduced the "reversing" rule.

\section{Discussion of Buriram pieces}

These pieces are owned by an individual collector in Bangkok (Figure 16) (Thammapreechakorn and Kritsadapinsri 1996). These pieces were made at a kiln in Buriram Province, northeastern Thailand, and they are believed to have been made at the beginning of the 12th century as the oldest estimate and in the early 13th century as the newest estimate. Besides the 17 pieces, Makruk pieces produced in different times and different kilns are owned. Different from the pieces that have been introduced so far, there is the characteristic that pieces considered to be Ma pieces from their form have a slightly abstract shape (Figure 17). In addition, including Ma pieces, the middle part of some pieces, including the base part, is quadrangular, which is different from the majority of Makruk pieces that are made as a

\footnotetext{
${ }^{3}$ There are large pieces having a similar form, but it is impossible to make clear the combination with other pieces, so there is no conclusive evidence to determine the what kinds the pieces are.
} 


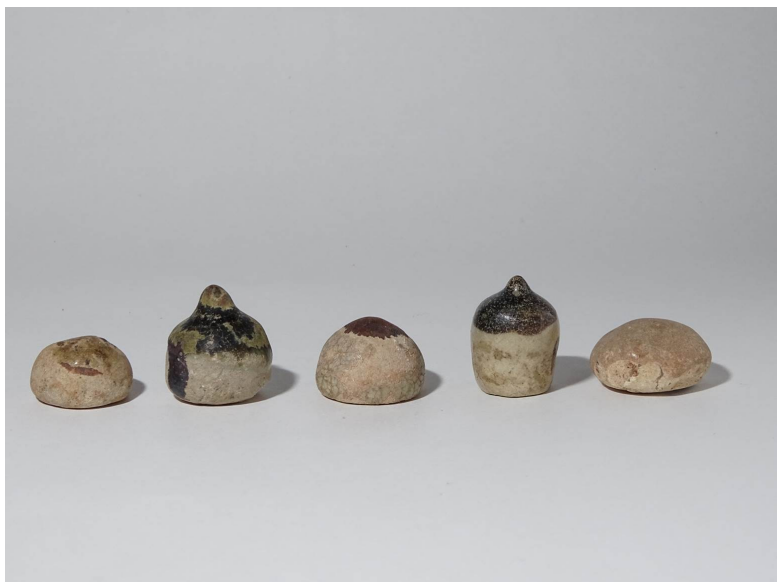

Figure 14

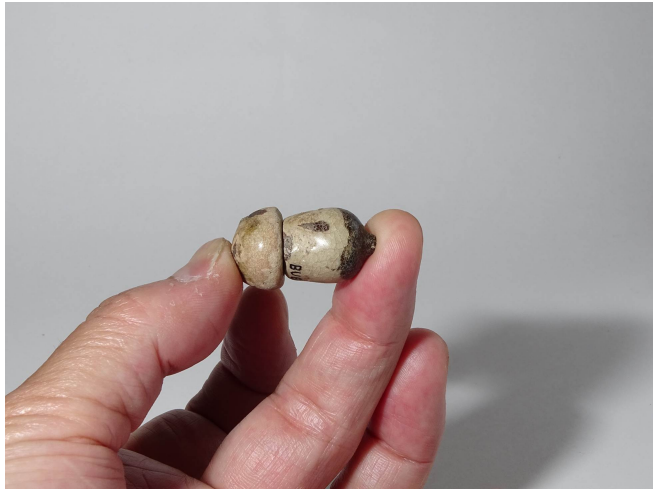

Figure 15

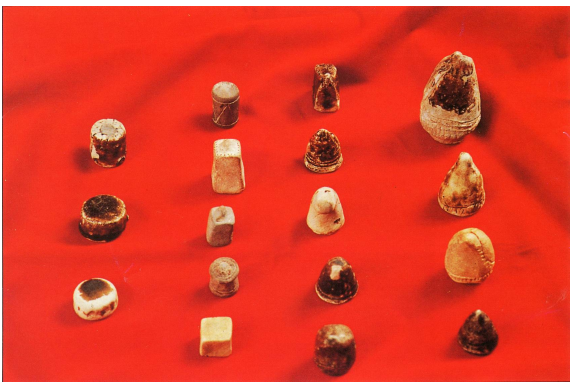

Figure 16

Board Game Studies Journal 11, pp. 53-71 DOI $10.1515 /$ bgs-2017-0002 


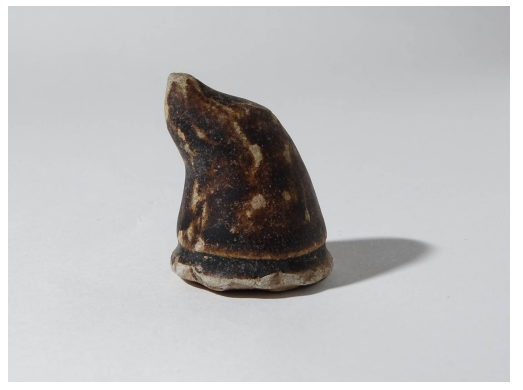

Figure 17

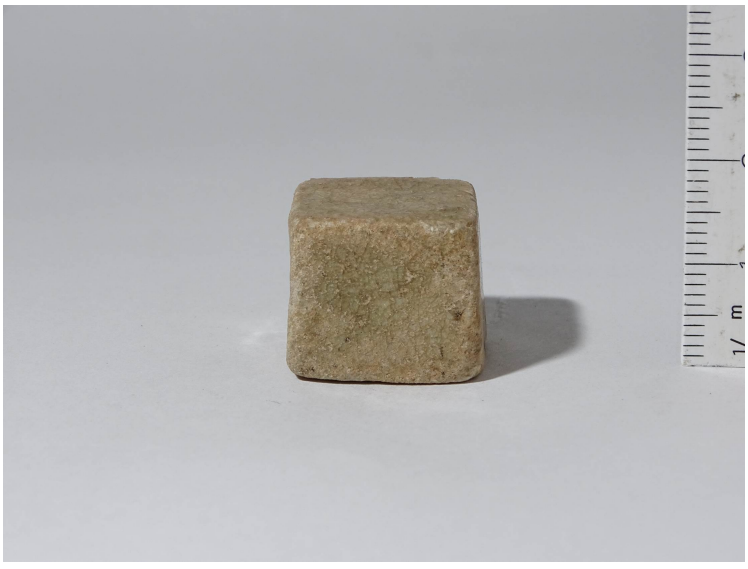

Figure 18

rotating body. Therefore, these pieces are difficult to define, while there is one possible Bia piece having an almost cubic shape (Figure 18). If the piece is a Bia piece, reversing a promoted piece is possible. Besides this, there is a possible piece having a cylindrical shape (Figure 19), and if it is a piece, the reversing rule could be applied. In addition, there are two short cylindrical pieces whose base diameter is about 2.5 centimeters (Figure 20. Compared to the sizes of the other Buriram pieces, the pieces are highly likely to be equivalent to Ruea pieces. In addition, from the flat shape, the possibility that the piece was used for saka the Thai version of the board game sugoroku or another game should be considered (Figure 21). 


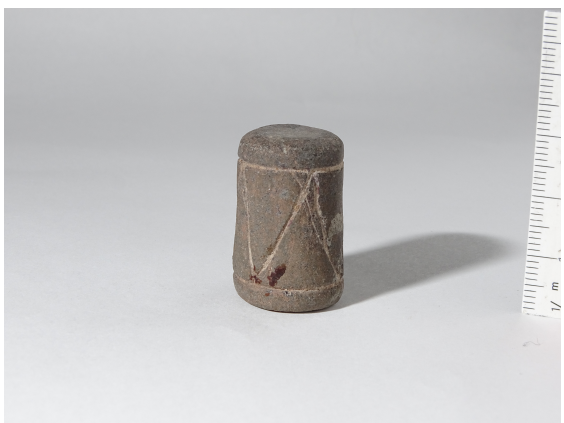

Figure 19

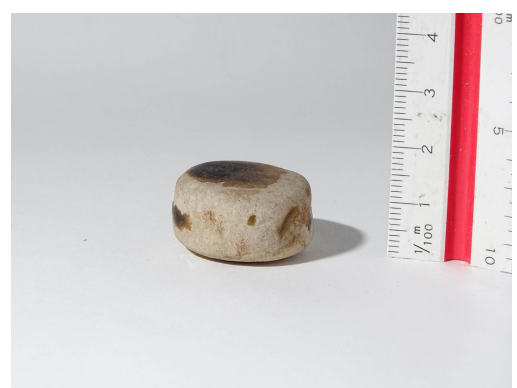

Figure 20

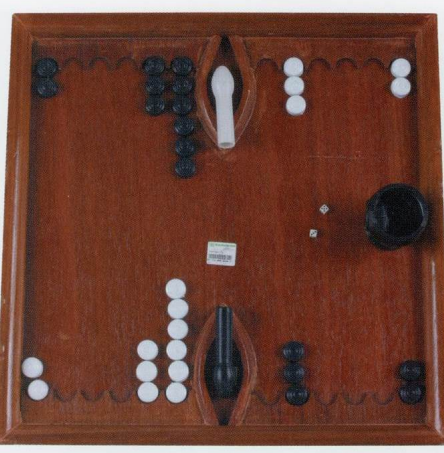

Figure 21 


\section{Conclusion}

As for the Kalong pieces that were used in Makruk, the reversing rule of promoted pieces equivalent to pawns is unlikely to have been employed in the 15 th and 16 th centuries. This is in contrast to the fact that the rule was applied to the Kohfukuji Temple pieces in Japan in the late 11th century (Shimizu and Oguri 1992). The rule, which is a very simple idea depending on the form of the pieces, was established in the early 11th century or before in Southeast Asia, accepted in southern China, and then introduced to Japan. Despite this, it is quite unlikely that the rule was not employed by Makruk in the Lan Na Kingdom in northern Thailand. However, among the Buriram pieces, there is one possible quadrangular Bia piece, and it has a reversible form. Even so, while it is obvious from the fact that the Buriram pieces were produced in the period from the beginning of the 12th century to the early 13th century, and from the forms of China's Xiangqi pieces, it should be noted that even though pieces have a reversible form, there are some cases to which the reversing rule of promoted pieces does not apply.

1. Among ceramic pieces in the 15 th and 16th centuries, there are no pieces resembling shells. So, it can be assumed that the use of shells for Bia pieces was introduced in relatively recent times.

2. Among the Kalong pieces, there are no possible Bia pieces that can be reversed.

3. Among the Buriram pieces, there is a possible Bia piece that can be reversed.

4. The fact that there is no possible Bia piece that can be reversed among the Kalong pieces in the 15th and 16th centuries could serve as circumstantial evidence that the establishment of the reversing rule of promoted pieces equivalent to pawns in Southeast Asia does not date back to very old times.

5. As for the Bangkok Museum pieces and Kalong pieces, only the Ma pieces have a representational shape. In addition to this fact, considering similarities between the current Makruk pieces and the Bangkok Museum pieces/ Kalong pieces in terms of some forms of Ruea pieces, it can be considered that both are Makruk pieces.

The above-mentioned points are important findings in this study. The number of materials of the Kalong pieces is relatively large, so it is easy to 
conduct a study. However, it is regrettable that the number of materials of the Buriram pieces is small, and the pieces are purchased items without any information about the ruins from which they were excavated, the same as the Bangkok Museum pieces, which puts limitations on the study. In addition, there is no set of Makruk pieces buried in a grave as burial materials, which makes it difficult to determine the kinds of pieces besides Ma and Ruea pieces. This presents an obstacle to a comparative study. Therefore, though unfortunate, the study failed to absolutely deny the Southeast Asia theory. However, I believe that the study successfully showed the possibility of refuting the foundation of the theory that assumes the existence of Shogilike games in Southeast Asia even in the periods when relevant materials do not exist.

\section{Acknowledgements}

This research was supported in part of a grant from Hayao Nakayama Foundation for Science \& Technology and Culture, and The Institute of Amusement Industry Studies.

\section{References}

Falkener, E. (1892). Games Ancient and Oriental and How to Play them. London.

Kimura, Y. (2001). Nisennen no Shogishi. 木村義徳2001『二千年の将棋史 一持ち駒使用の謎一』日本将棋連盟. Tokyo.

Masukawa, K. (1977). Shogi. 増川宏一1977『将棋』法政大学出版局. Tokyo.

Matsuoka, N. (2009). "Shogidenrai no Nazo ni Idomu Jo". In: Shogipenkurabu 51. 松岡信行 $2009\lceil$ 将棋卮来の『謎』に挑む (上)」『将棋ペンクラ ブ』2009年春第51号 将棋ペンクラブ.

Murray, H. J. R. (1913). A History of Chess. Oxford.

Ouchi, N. (1986). Shogi no Kitamichi. 大内延介1986『将棋の来た道』めこ ん社. Tokyo.

Randolph, A. (1971). 'Shogi to Chesu no Ichimen' Shogisekai Sangatugo. ラ ンドルアレックス1971「将棋とチェス (1)将棋とチェスの歴史の一 面」『将棋世界』3月号 日本将棋連盟. Tokyo.

Shimizu, Y. (2013). "Shogidenraisaiko". In: Kokogakuronko 36. 清水康二2013 「将棋伝来再考」『考古学論攻』第36冊, 奈良県立橿原考古学研究所. 
Shimizu, Y. and A. Oguri (1992). 'Kofukujikyukeidaihakkutsuchosagaiho' In Narakenisekichosagaiho 1992nendo Daiichibunsatsu. 清水康二 ·小栗明 彦1993「興福寺旧境内発掘調査概報」『奈良県遺跡調査概報1992年度 第一分冊』奈良県立橿原考古学研究所. Kashihara.

Thammapreechakorn, P. and S. Kritsadapinsri (1996). Ceramic Art in Thailand. Bangkok. 